\title{
História e história local: desafios, limites e possibilidades
}

History and Local History: Challenges, Limits and Possibilities

Erinaldo Cavalcanti*

\section{Resumo}

Este artigo tem por objetivo ampliar as discussões sobre a chamada história local como objeto de estudo e, também, como categoria conceitual para o ensino e/ou a historiografia. Almeja, por conseguinte, problematizar alguns sentidos e significados que são atribuídos à história local e demonstrar alguns dos desafios que se apresentam para as diferentes apropriações pelas quais tem sido mobilizada.

Palavras-chave: História; História local; aportes conceituais.

\begin{abstract}
This article aims to expand the discussions about the so-called local History, as an object of study and as a conceptual category for the History teaching and for its research. Therefore, the article aims to problematize some of the meanings and senses that are attributed to local History and to show some of the challenges arisen for its different appropriations.
\end{abstract}

Keywords: History; local History; conceptual contributions.

O escritor Graciliano Ramos, ao se referir ao processo de produção da escrita, faz uma analogia entre o ato de escrever e o ofício das lavadeiras de roupas do estado de Alagoas:

Deve-se escrever da mesma maneira com que as lavadeiras lá de Alagoas fazem em seu ofício. Elas começam com uma primeira lavada, molham a roupa suja na beira da lagoa ou do riacho, torcem o pano, molham-no novamente, voltam a torcer. Colocam o anil, ensaboam e torcem uma, duas vezes. Depois enxáguam, dão mais uma molhada, agora jogando água com a mão. Batem o pano na laje ou na pedra limpa, e dão mais uma torcida e mais outra, torcem até não pingar do pano uma só gota. Somente depois de feito tudo isso é que elas dependuram a

\footnotetext{
* Doutor em História pela Universidade Federal de Pernambuco (UFPE), professor Adjunto da Faculdade de História e do mestrado interdisciplinar da Universidade Federal do Sul e Sudeste do Pará (Unifesspa). Marabá, PA, Brasil. ericontadordehistorias@gmail.com
} 
roupa lavada na corda ou no varal, para secar. Pois quem se mete a escrever devia fazer a mesma coisa. A palavra não foi feita para enfeitar, brilhar como ouro falso; a palavra foi feita para dizer. (Ramos, 1962)

Tomando como inspiração e desafio essa "exegese” de Graciliano Ramos, gostaria de iniciar as reflexões mencionando o lugar da produção para o qual essas palavras foram "lavadas" e, sobretudo, pôr em destaque a importância e o cuidado com o manuseio dos significados das palavras, pois, como ressaltou o escritor alagoano, "a palavra não foi feita para enfeitar, brilhar como ouro falso; a palavra foi feita para dizer" (Ramos, 1962).

Uma parte deste texto foi construída para ser apresentada no I Encontro de História do Sul e Sudeste do Pará, cuja temática central foi: "O local e global: o lugar dos direitos na sociedade globalizada". ${ }^{1}$ Nessa dimensão, ele apresenta as marcas também desse "local". Outro espaço que também grafou marcas neste texto diz respeito às reflexões vivenciadas na disciplina "Prática Curricular Continuada I: ensino de história local e regional", que lecionei no curso de Licenciatura em História da Universidade Federal do Sul e Sudeste do Pará (Unifesspa).

O tempo - e suas distintas temporalidades - tem sido apropriado e mobilizado de diferentes maneiras pela ciência histórica. Os usos do passado, apropriados no presente pela História e seu ensino, têm se modificado substancialmente em diferentes sentidos e direções. Diferentes estratégias de pesquisa e ensino têm mobilizado distintos vestígios das experiências temporais como metodologias de estudo e/ou objeto de trabalho. Nesse movimento, insere-se uma rica variedade de trabalhos que versa acerca das relações entre História, ensino e patrimônio; ${ }^{2}$ História, ensino e literatura; ${ }^{3}$ ensino de história e novas tecnologias da informação; ${ }^{4}$ História, ensino e tempo presente ${ }^{5}$ e História, ensino e história local, ${ }^{6}$ para citar apenas alguns.

Essas diferentes apropriações se constituem, por conseguinte, em distintas maneiras de ler e interpretar o tempo por meio dos indícios, dos sinais e vestígios $^{7}$ que são mobilizados. Nesse sentido, eu gostaria de expandir o debate acerca de uma dessas dimensões com o objetivo de contribuir e ampliar as reflexões. Para tanto, centrarei as discussões, problematizando alguns desafios sobre os usos da chamada história local para sua apropriação no campo do ensino e no campo da pesquisa historiográfica. 


\section{O “Local” COMO ESPAÇO DE PROBLEMATIZAÇÃo}

Há uma citação bastante conhecida do filósofo e matemático francês Blaise Pascal: "Uma cidade, um campo, de longe são uma cidade e um campo, mas à medida que nos aproximamos, são casas, árvores, telhas, folhas, capins, formigas, pernas de formigas, até o infinito. Tudo isso está envolto no nome campo" (Pascal, apud Gonçalves, 2007, p.175).

Essa citação de Pascal nos coloca uma série de possibilidades para pensar nas discussões que o "local" pode suscitar para os debates envolvendo sua apropriação pela História e seu Ensino. O que se entende por local? Local em relação a quê? Para quem? O que é local para uns pode, igualmente, ser global para outros. O reordenamento na vida de famílias que são afetadas pelas atividades da mineração, no sul do estado do Pará, por exemplo, trata-se de uma questão local? Se estivermos falando de trabalhadores e trabalhadoras que vivem em uma vila que foi afetada pelas ações da extração do minério, poderíamos afirmar que se trata de uma história local?

Em que dimensões seria uma história local, já que essas histórias são construídas, atravessadas, redirecionadas e ressignificadas com os desdobramentos da extração de minério, atividade desenvolvida com todas as relações de poder do chamado capitalismo globalizado? Em que dimensões poderíamos nomeá-la de história local, haja vista que sua configuração é resultante de diferentes forças, atores e empresas ligadas ao mercado internacional da mineração? Nesse sentido, onde estabelecer as demarcações? Como e até onde instituir os limites e as fronteiras, mesmo sendo estas móveis e elásticas? Há como precisar onde termina a história local e começa a história "não local" ou história global? Até que ponto e como o local e o global se articulam e se interconectam?

As discussões que aqui apresento não pretendem "inventar a roda" no âmbito dos debates que envolvem a chamada história local e suas relações com a História e seu ensino. Se servirem para demonstrar a complexidade exigida para tornar inteligível seu uso, terá atingido seu objetivo. Nesse sentido, irei revisitar alguns debates promovidos por estudiosos que se dedicaram a estudar a história local, sobretudo nos diálogos estabelecidos com o ensino de História. Nesse percurso, levantarei algumas indagações para as quais não tenho respostas, senão, outros questionamentos. 
Nessa dimensão, gostaria de trazer à discussão alguns sentidos atribuídos à palavra "local". A etimologia da palavra nos leva ao latim localis. Sua grafia - que pareceria um plural, embora não o seja - já sugere evitarmos apreendê-la ou aprisioná-la em um sentido singular. Sugere que ela desfruta de significados plurais. Ou seja, o local, desde a gestação de sua grafia, é um espaço conceitual polissêmico; é um lugar polifônico. No conhecido dicionário Aurélio, a palavra "local" encontra-se experimentada como sinônimo de "lugar". De maneira mais detalhada, o primeiro significado atribuído a "local" diz respeito a um sentido "relativo a determinado lugar". Assim, os significados de "local" estão embrionariamente ligados a uma concepção de lugar e, nessa relação, "lugar" está indissociável de espaço. Ou seja, ao falarmos de local, estamos, concomitantemente, falando de espaço.

Para o sociólogo e urbanista francês Alain Bourdin (2001), o "local” é um lugar de sociabilidades, marcado pela proximidade e pela contiguidade das relações entre os sujeitos que as estabelecem. Nessa perspectiva, a "dimensão do local” permite ampliar e compreender a relação entre espaço e ação, ou pensar e problematizar o espaço como lugar de ação, o que coloca, por conseguinte, a relação sujeito/espaço no centro das discussões. Nesse sentido, o "local" seria um recorte eleito por aquele que desejasse refletir sobre as experiências dos sujeitos em espaços sociais delimitados. Portanto, o local, nessa acepção, está sendo instituído pelo professor/pesquisador. ${ }^{8}$ É ele o sujeito autor desse espaço conceitual.

Por essa linha de raciocínio, é oportuno trazer Michel de Certeau à discussão quando ele afirma que a relação que liga "as discussões aos lugares" é uma ação propriamente do historiador. Em suas palavras, "o gesto que liga as 'ideias' aos lugares é, precisamente, um gesto de historiador. Compreender, para ele, é analisar, em termos localizáveis, o material que cada método instaurou inicialmente segundo seus métodos de pertinência” (Certeau, 2007, p.65, grifo no original).

Diante do exposto, cabe questionar: seria "local" um conceito? Se a resposta for "sim", em que consistirá, então, uma "história local"? Em que se distinguiria de uma "história não local"? Se a resposta for "não", em quais circunstâncias caberia o uso da expressão "história local"?

Acredito ser importante, primeiramente, termos clareza sobre o que entendemos pelo conceito de "local" e, sobretudo, por "história local". Não se 
trata, portanto, de mera retórica a discussão em tela. Pelo contrário. Trata-se de problematizar esses conceitos e compreender seus significados para, assim, podermos manuseá-los de forma coerente e, por conseguinte, direcionar seus usos de maneira a fazer-se dizer o que precisa ser dito, como destacou Graciliano Ramos.

Nesse movimento, parece-me oportuno trazer à discussão as análises promovidas pelo historiador alemão Reinhart Koselleck acerca da história dos conceitos. Seja como método ou disciplina, a história dos conceitos, para ele, se encarrega de problematizar a crítica "com particular empenho de expressões fundamentais de conceito social ou político” (Koselleck, 2006, p.103).

Um conceito encontra-se intimamente ligado a uma palavra, mas nem toda palavra está ligada, necessariamente, a um conceito. Koselleck, ao discorrer acerca da relação palavra-conceito e conceito-palavra, destaca que "conceitos sociais e políticos contêm uma exigência concreta de generalização ao mesmo tempo que são sempre polissêmicos" (Koselleck, 2006, p.108). Por esse ângulo de percepção, os conceitos são detentores de uma polissemia de sentidos e possuem a capacidade de agregar uma multiplicidade de significados. Paradoxalmente, contêm um caráter homogeneizante, para usar de empréstimo as palavras desse autor.

Um conceito não é forjado sem lutas, disputas e trocas, sejam essas políticas ou semânticas. Assim, a formação processual dos conceitos representa, antes de tudo, lutas políticas que legitimam posições, demarcam espaços, instituem direitos e significados; os conceitos são forjados em um tenso campo de forças. A "batalha semântica", segundo Reinhart Koselleck, "para definir ou impor posições políticas e sociais em virtude das definições está presente, sem dúvida, em todas as épocas de crise registradas em fontes escritas" (Koselleck, 2006, p.102). Em outras palavras, entender como os conceitos são forjados é compreender as lutas políticas pelas lentes das disputas semânticas.

Nesse sentido, irei problematizar algumas dimensões que concorrem para atribuir significados à chamada história local e, por conseguinte, demonstrar os desafios do seu uso conceitual, o que não inviabiliza sua utilização, diga-se de imediato.

As discussões acerca da história local não são recentes e aparecem nas reformas curriculares de 1930, como destaca Maria Auxiliadora Schmidt (2007). Estavam presentes, também, no Parecer 853 do Conselho Federal de 
Educação de 1971, quando faz referência à história local como um recurso didático. Aquele documento que agregava as atividades de geografia e história "privilegiava o estudo do mais próximo e mais simples deslocando-se depois para o mais distante e mais complexo" (Schmidt, 2007, p.188). Em 1990, os Parâmetros Curriculares voltam a tratar da história local, sendo ela apropriada "como um dos eixos temáticos dos conteúdos de todas as séries iniciais da escola fundamental e como perspectiva metodológica em todas as séries da escola básica" (2007, p.189).

A professora e historiadora Circe Bittencourt, por sua vez, ressalta que "a história local tem sido indicada como necessária para o ensino por possibilitar a compreensão do entorno do aluno, identificando o passado sempre presente nos vários espaços de convivência - escola, casa, comunidade, trabalho e lazer - igualmente por situar os problemas significativos da história do presente" (Bittencourt, 2009, p.168). Seguindo sua reflexão, ela destaca, todavia, os cuidados para evitar que a história local não reproduza em escala menor a mesma narrativa de uma história feita pelos "grandes" e "importantes" personagens do poder político e das classes dominantes locais. Nesse sentido, é importante que a história local não se limite a reproduzir, em dimensões micro, o estudo da vida e das atividades de prefeitos e demais autoridades de determinado lugar, por exemplo. Para evitar essas armadilhas, "é preciso identificar o enfoque e a abordagem de uma história local que crie vínculos com a memória familiar, do trabalho, da migração, das festas..." (Bittencourt, 2009, p.169).

\section{DesAfios}

Desafio 1: História local como "história pequena"

Um dos desafios que se apresentam na utilização do conceito de história local diz respeito a um conjunto de significados que a institui em uma relação de oposição aos considerados grandes fatos ou acontecimentos. Nesse sentido, a história local seria, por excelência, uma "história pequena", ou história miúda. Não pequena em importância ou significado, diga-se à exaustão. Por "história pequena" me refiro a uma dada leitura que sugere uma interpretação pela qual uma história (ou várias histórias) é apreendida e percebida pela extensão espacial de seus desdobramentos; que não excederia grandes limites 
geográficos. O conhecimento de existência dessa história não ultrapassaria grandes alcances, além dos imediatos limites no espaço físico onde ocorrera.

Para a historiadora Márcia Gonçalves, a diversificação que configura o que se identifica e se reconhece como local é marcada pela multiplicidade de sentidos e variações. Ela ressalta que "o local pode ser associado a uma aldeia, a uma cidade, a um bairro, a uma instituição - escolas, universidades, hospitais - e, como escolha por vezes recorrente, a um espaço político administrativo, como distrito, freguesia, paróquia, municipalidades" (Gonçalves, 2007, p.177).

Por essas lentes interpretativas, a história local se constituiria, principalmente, em uma espécie de "acontecimento pequeno", circunscrita a uma limitação espacial, sobretudo porque os relatos sobre sua ocorrência ficariam quase sempre reduzidos a uma pequena dimensão geográfica. Essa interpretação nos coloca uma série de desafios. Podemos afirmar que as histórias de um bairro da cidade de Marabá (PA) - ou de qualquer outra cidade - podem ser consideradas como história local com base em quê? As histórias de uma rua poderiam ser consideradas como local em relação às histórias do bairro? Nessa relação, como seriam classificadas as histórias do bairro? A mesma interpretação poderá ser estendida para a relação bairro/cidade, cidade/município, município/estado, estado/país, e assim por diante. Nessa perspectiva, o que e como definir como local? Talvez seja esse o maior desafio.

Trazer essas problematizações não implica que a questão esteja solucionada. Longe disso. Até porque também não teríamos, ainda, elementos que definiriam os fundamentos para classificar uma história como pequena, como miúda. Qual o referente e quais os fundamentos epistemológicos para assim classificar uma história, um acontecimento?

\section{Desafio 2: História local como "história do entorno"}

Outro desafio reside na interpretação em que se apreende a chamada história local como uma "história do entorno". Por esse ângulo de percepção, a história local seria uma história "próxima”, não só no espaço, mas também no tempo. Porém, próxima a quem ou ao quê? Uma história do entorno de quem e do quê?

Circe Bittencourt chama a atenção para essa questão e destaca que "é comum falar de história local como a história do entorno, do mais próximo, do bairro ou da cidade" (Bittencourt, 2009, p.171). Nessa dimensão, tratar-se-ia 
de um acontecimento próximo ao professor/pesquisador, na medida em que esse conhece as pessoas, as histórias do bairro, da rua, da aldeia? Seria essa uma história local porque se acha relativamente próxima ao professor e/ou pesquisador quando se encontra nas cercanias do objeto estudado e mantém, com ele, relações de pertencimento? Ou seria uma história em que os acontecimentos estudados encontram-se próximos no tempo, quando a história estudada ou ensinada, além de ser a ela atribuída uma concepção de "pequena" (porque do bairro ou da rua, por exemplo), seria local também porque os atores protagonistas são contemporâneos aos/às pesquisadores/as e emprestam suas memórias como objeto e fonte das pesquisas que desenvolvemos?

Os trabalhos que versam acerca da chamada história local - no ensino ou na pesquisa (ou em ambos) - fazem uso recorrente da memória. Nessa perspectiva, demonstram que a história local e a memória se encontram interconectadas, sobretudo quando esta se constitui como fonte documental e/ou objeto de pesquisa daquela. Para Circe Bittencourt (2009, p.169), "a questão da memória impõe-se por ser a base da identidade, e é pela memória que se chega à história local", mesmo que muitos trabalhos, enfatiza ela, se constituam mais como um trabalho de memória do que de História.

Entretanto, essa reflexão da professora Circe Bittencourt precisa ser analisada com cautela para evitar análises apressadas, sobretudo quando ela refere que "pela memória se chega à história local" (Bittencourt, 2009, p.169). Cautela no sentido de evitar uma interpretação segundo a qual a história local estaria em um dado lugar e seria descoberta pelas veredas da memória. Ou seja, é importante evitar qualquer leitura que compreenda a existência, a priori, da história local, como se ela "se encontrasse lá", pronta e definida, à espera do professor/pesquisador para desbravá-la, descortiná-la e, assim, fazê-la aparecer. Nada mais enganoso. Não existe essa história local que aguarda ser descoberta pelo professor/pesquisador. Nem tampouco há caminhos preestabelecidos, predefinidos, que garantam ter acesso a essa ou àquela história.

Essa concepção que institui a história local como uma história próxima - ou do entorno - pode implicar uma interpretação reducionista do que seria local e, por extensão, história local. Para a professora e historiadora Maria Auxiliadora Schmidt, essa leitura interpretativa pode se tornar "mais grave ao se levar em consideração os perigos do anacronismo - o desenvolvimento de perspectivas etnocêntricas, reducionistas, localistas, bem como o perigo 
de identificação do local com o mais próximo, o mais conhecido, estabelecendo-se uma relação mecânica entre o mais próximo e o mais conhecido" (Schmidt, 2007, p.190).

Se concordarmos que o "local" é, por excelência, o espaço de experiências da vida cotidiana de homens e mulheres, e, por conseguinte, o lugar de atuação de diferentes sujeitos, esse se torna, portanto, um espaço privilegiado para problematizar as relações homem/espaço, conforme defende Alain Bourdin (2001). Por essa leitura interpretativa, o local como campo de microrrelações entre homens/homens e homens/espaço, o conceito de redução de escala de observação, proposto pela micro-história, pode se apresentar como uma ferramenta metodológica viável ao seu estudo. Concepção também defendida pela professora Márcia Gonçalves (2007). Para ela, as análises do "local" proporcionam outros efeitos de conhecimento nas diferentes especificidades, deslocam hierarquias e sobreposições entre nacional e regional e possibilitam repensar as relações entre as categorias centro/periferia.

Entretanto, não podemos fazer aproximações rápidas que levem a conclusões superficiais, como se já existissem aproximações estabelecidas a priori entre micro-história e história local. É oportuno destacar, como ressaltou Giovanni Levi, que "para a micro-história, a redução da escala é um procedimento analítico, que pode ser aplicado em qualquer lugar, independentemente das dimensões do objeto analisado" (Levi, 2011, p.139). Ou seja, a micro-história não é definida por um objeto específico, nem por suas microdimensões, como costuma ser representada a história local - como uma história "pequena" ou do "entorno", para citar apenas esses dois significados que a ela são atribuídos. ${ }^{9}$

Desafio 3: História local como conjunto coeso e diminuto de relações, passível de ser estudada em sua "totalidade"

Outro desafio resulta da concepção que compreende a história local como um conjunto coeso e diminuto de relações e, por isso, seria possível estudá-la em sua totalidade. Não é difícil encontrarmos reflexões que fazem uso da chamada história local - sobretudo quando a temática de ensino ou pesquisa é um bairro, uma comunidade ou uma vila, por exemplo - por meio de objetos de ensino ou pesquisa, como se esses se constituíssem, praticamente, sem 
conflitos. Às vezes, os conflitos aparecem de forma suavizada ou minimizada, como se nas relações de poder, nesses espaços estudados, inexistissem confrontos, disputas, alianças e enfrentamentos. São leituras que, talvez, por apreenderem o que se denomina história local como algo "pequeno", com sujeitos ligados por laços de pertencimentos, representam-na como histórias cujas relações seriam marcadas, predominantemente, pela harmonia das relações. Por conseguinte, essa ilusão da ausência de conflito, às vezes, desdobra-se em narrativas que têm a pretensão de dar conta da totalidade das relações envolvidas nas histórias ensinadas e/ou pesquisadas.

A compreensão de que é possível estudar a chamada história local em sua "totalidade" pode concorrer para análises generalizadoras. Por extensão, pode contribuir para que certos comportamentos de atores ou de parcelas específicas de segmentos sociais sejam associados de modo como se fossem extensivos a todas as relações dos grupos sociais envolvidos. As análises do historiador Samuel Raphael podem contribuir para evitarmos certas generalizações. Para ele, o pesquisador "poderá escolher como ponto de partida algum elemento da vida que seja, por si só, limitado tanto no tempo como no espaço, mas usado como uma janela para o mundo" (Raphael, 1990, p.229). Essa sugestão pode evitar a ideia de generalização, que não raro se atribui à comunidade ou à localidade, como se determinadas dimensões, aspectos ou circunstâncias presentes em certos relatos de memória, ou em outro documento, representassem um todo das relações. Talvez por ser apreendido como algo "menor" em dimensões espaciais, credita-se ao estudo do local a possibilidade de ser ele analisado em totalidade. Erro crasso.

Essa dimensão, por conseguinte, desdobra-se em outra, qual seja, a concepção que apresenta a possibilidade de se compreender a chamada história local estudando-a isoladamente. Schmidt chama a atenção para os cuidados em evitar que a história local seja apreendida como se fosse autoexplicativa em si mesma, ou seja, como se para compreender o que se denomina história local bastasse o estudo ou pesquisa dela mesma, desconsiderando as redes de relações em que os acontecimentos são construídos, sobretudo no chamado mundo globalizado. Nessa dimensão, a autora ressalta que "é importante observar que uma realidade local não contém, em si mesma, as chaves de sua própria explicação" (Schmidt, 2007, p.190). 
Desafio 4: História local determinada pelo espaço geográfico

Se a história local possibilita uma proximidade entre sujeitos - sejam eles professor/pesquisador ou estudantes nas relações com os objetos de ensino ou pesquisa -, parece que a ela ainda se atribui certa concepção que a institui como determinada pelo espaço geográfico. Parece-me que as discussões sobre "local" e, por conseguinte, sobre a história local, ficam, predominantemente, sob a égide da dimensão espacial, circunscrita aos limites físico-geográficos quase sempre apreendidos como pequenos, como já ressaltado.

Nessa dimensão, a história local se constituiria como uma "história espacial", especialmente pequena, compreendendo espaço como sinônimo de "local”. Essa dimensão seria sua marca de distinção. Entretanto, não podemos esquecer que toda experiência é espacial. As pesquisas que desenvolvemos analisam objetos sobre acontecimentos diversos que ocorreram em algum local, independentemente do conceito que adotemos. Os temas que trabalhamos em sala de aula, os assuntos/conteúdos que ensinamos, versam sobre representações acerca de acontecimentos que ocorreram em algum espaço, em algum local.

Não existe, portanto, experiência/acontecimento fora de um espaço, fora de um lugar, fora de um local. Talvez o fato de que a expressão "história local" contenha uma palavra que é sinônima de espaço ("local") direcione certa concepção que atribui àquele conceito uma dada interpretação que o institui de maneira que a chamada história local seja tutelada ou condicionada pela dimensão espacial. Entretanto, o que institui que um acontecimento seja considerado local não é a dimensão do espaço, nem a dimensão do tamanho, pois quem institui a dimensão, a legitimidade, o reconhecimento e a representação é a dimensão política do acontecimento.

Desafio 5: História local como uma extensão e um desdobramento da história "não local" (nacional?)

Essa interpretação apreende e representa a história local como uma extensão, um desdobramento de uma história "não local” (história nacional?), como se fosse peça de um quebra-cabeça. Nessa dimensão, ela teria de se constituir e se apresentar de forma harmônica e, assim, permitir o "encaixe" na história maior. 
Por meio dessa leitura interpretativa a história local seria, portanto, uma "pequena peça" de um organograma maior, e o professor ou pesquisador iria apresentar em que dimensões ela corresponderia à história nacional. Em outras palavras, ela seria uma consequência da "história não local", um prolongamento em dimensões reduzidas e, assim, teria de manter com a "história nacional" uma relação de causa e efeito. Portanto, aquilo que ocorreu no âmbito nacional provocou os efeitos e as consequências que determinaram, em dimensões micro, a configuração da história local.

Esses últimos significados atribuídos ao que se convencionou chamar de história local parecem se encontrar presentes em todas as outras leituras interpretativas mencionadas anteriormente. Assim, seja entendendo a história local como uma história "pequena" ou como uma história "do entorno", como uma história "coesa e passível de ser estudada em sua totalidade", uma história como "consequência de outra história 'maior", é recorrente a interpretação que associa a história local a um espaço físico-geográfico, em uma relação de determinação. Ela é, quase sempre, apresentada como determinada por essa dimensão do espaço. É história local porque é "do bairro", “da rua”, "da vila”, "da escola".

Eu gostaria de ressaltar, todavia, que essas interpretações acerca da chamada história local nem sempre aparecem de maneira explícita, assim como não estão presentes em todos os trabalhos de professores e/ou autores que fazem uso da história local como objeto de ensino ou pesquisa. Há importantes reflexões e relatos de experiência - apresentados em revistas e/ou congressos - sobre a temática em tela, como demonstra a literatura especializada.

\section{HistóRIA LOCAL: OBJETOS, DOCUMENTOS E ABORDAGENS}

O historiador Raphael Samuel apresenta uma discussão problematizando as possibilidades de trabalho que envolvem a chamada história local na relação com a história oral. Nessa dimensão, ele destaca que a história local dá ao pesquisador uma ideia muito mais imediata do passado. Os indícios das experiências do passado apresentam suas faces na esquina, na rua, na padaria. Anunciam seu som no mercado, e apresentam suas impressões nos grafites das paredes amareladas pela presença do tempo. Nas palavras do autor, a "história local tem também a força popular, tanto como uma atividade, quanto como 
uma forma literária" (Samuel, 1990, p.221). Nesse sentido, os registros documentais que oferecem esses indícios são potenciais possibilidades de estudo para se analisar parte do universo polissêmico constitutivo da chamada história local. O autor chama a atenção para a possibilidade de trabalhos com os jornais municipais, que seriam importante fonte para o trabalho.

Como meu objetivo é problematizar os desafios do uso da chamada história local, poderíamos ampliar as discussões e colocar em debate, por exemplo, a questão: o que se configura como jornal municipal? Pergunta aparentemente simples e demasiado óbvia, até. Entretanto, todo periódico é municipal, pois é produzido em algum município, salvo os jornais do Distrito Federal. Os jornais Folha de S. Paulo, O Globo e o Diário de Pernambuco, por exemplo, também são municipais, como o é O Correio Tocantins ${ }^{10}$ ou o Jornal Vanguarda. ${ }^{11}$ Entretanto, as relações políticas e editorais daqueles, diferentes destes últimos, em termos de produção, circulação, visibilidade e inserção nas relações sociais, os fazem ultrapassar amplamente as fronteiras municipais. Nessa dimensão, seria importante compreendermos com clareza o que se entende por jornal municipal. Um periódico cuja circulação se restringe aos limites fronteiriços do município? Uma questão a ser problematizada.

Raphael Samuel apresenta uma grande quantidade de documentos que possibilitam o estudo do que nomeia como história local. Registros resultantes de atividades de rádio locais, moedas antigas, cartões-postais e dos dias dos namorados, cartas pessoais, livros de batismo das paróquias e livros de prêmios da escola do bairro, para citar alguns exemplos. São registros que, sem dúvida, oferecem possibilidades de estudo para uma variada gama de objetos. Entretanto, são colocados em uma perspectiva segundo a qual o local se define, prioritariamente, pela dimensão espacial de proximidade e tamanho. A rádio é local por ter um alcance relativamente pequeno e residir no bairro ou na cidade, também pequenos. $\mathrm{O}$ mesmo fundamento serve para pensar os demais registros documentais apresentados.

Raphael Samuel, ao discutir a diversidade documental que pode alimentar os estudos sobre a história local, faz referência à categoria de "documento local". Nessa dimensão, caberia questionar: o que seria um documento local e, por extensão, o que seria um documento não local? Quais os princípios e as dimensões que caracterizariam um documento para receber o estatuto de "local"? 
Nos documentos oficiais, como os registros dos governos municipais seguindo a linha de raciocínio do historiador Raphael Samuel, e apreendendo "municipal" como categoria análoga à de "local" (o que implicaria uma série de outros desafios) -, a concepção do que é ser "local" traz consigo, de maneira mais perceptível, além dos aspectos físico/espacial, a dimensão política. Aqueles registros como leis, projetos de leis, resoluções e decretos, entre outros, fazem referência aos limites - em termos de extensão e aplicabilidade definidos politicamente acerca do campo de atuação do referido governo. Limites que são reconhecidos institucionalmente. Limites que apontam o raio de abrangência do poder e a atuação de um governo local. Entretanto, isso não significa dizer que as ressonâncias de ações executadas no âmbito municipal (ou local) não afetam espaços para além das fronteiras geográficas instituídas pelos limites políticos de um município.

Como venho tentando demonstrar, uma das principais dificuldades enfrentadas em relação à história local diz respeito à própria noção de história local, como também destacou Raphael Samuel. Para ele, essa dificuldade reside no fato de que o local é pensado "como uma entidade distinta e separada, que pode ser estudada como um conjunto cultural" (Samuel, 1990, p.227). Assim, a localidade é vista como um fenômeno único e homogêneo.

O espaço - seja ele nomeado como local ou global - é uma construção política e simbólica, antes de ser físico-geográfica, porque são as práticas políticas e as relações de poder que nomeiam, inventariam e produzem sentido, visibilidade e reconhecimento do espaço físico. O Congresso Nacional, do ponto de vista físico, é um prédio local, mas as relações que lá se praticam, sua importância e seu reconhecimento político o tornam nacional. Por esse ângulo de percepção, podemos questionar, por exemplo, que a Queda da Bastilha, ocorrida na França em 14 de julho de 1789, foi um acontecimento local, pois ocorreu no bairro de Saint-Antoine, no município de Paris. Entretanto, sua dimensão política, construída de forma relacional e heterogênea, sem determinismos a priori, sem prognósticos estabelecidos, tornou possível que seus desdobramentos ultrapassassem os limites do bairro, da cidade e do país. Dessa forma, aquele acontecimento ocorrido em um bairro da cidade de Paris, de maneira gradativa, passou a ser compreendido e apreendido como fazendo parte da História, sem a necessidade de nele ser inserido ou eliminado o adjetivo "local". 
Talvez a estratégia viável a ser experienciada consista em ter-se clareza do objeto de ensino ou pesquisa e dos recursos documentais disponíveis e, assim, definir o que é possível configurar como localidade - ou local - ou comunidade, seja qual for o conceito adotado. Com isso, não partir do conceito definido como "categoria estrangeira", pensada por historiadores que estudaram objetos de investigação distintos dos nossos, em uma tentativa de enquadrar o conceito pré-fabricado no objeto analisado ou ensinado.

Nessa dimensão, talvez o percurso pudesse ser experimentado no sentido inverso. O que os documentos permitem entender e configurar como local? Até onde eles permitem ir? Em termos de discussões sobre o espaço, poder-se-ia colocar a questão desta maneira: para compreender meu objeto de investigação ou de ensino, até onde posso considerá-lo como "local"? Até os limites da rua? Do bairro? Da minha cidade? Os documentos mobilizados para pesquisar ou ensinar o objeto específico podem sugerir pistas, indícios para essas questões. Como os homens e mulheres se colocam no tempo em relação a essas questões? Como se apropriam e representam? Como inventam, nomeiam e atuam nessas práticas e relações que inventariam o local? Como ressaltam Ossana (1994) e Schmidt (2007), levantar essas questões pode contribuir para que a chamada história local se constitua em experiência que amplie uma reflexão histórica compreendida como plural e heterogênea, potencializando suas singularidades para compreender as formas de atuação do homem no tempo e no espaço.

Mesmo que façamos esse percurso objeto/documento/conceito, ainda não resolveremos os desafios que o uso do conceito "história local" pode suscitar. O que definir como "local"? Com base em quê? Quais os critérios usados para instituir como história local a história que praticamos?

\section{CONSIDERAÇÕES FINAIS}

Diante dos desafios, ao invés de tentarmos definir a configuração de uma história local e assim estabelecer seus limites e demarcações, talvez pudéssemos pensar em compreender a "dimensão local da História" com que trabalhamos; dos acontecimentos que pesquisamos; das histórias que ensinamos. Ou seja, estaríamos trabalhando, pesquisando ou ensinando História, porém, preocupados em compreender sua configuração local. 
A configuração local da história, do meu ponto de vista, em nada se aproxima daquelas acepções atribuídas à história local. Ela não é uma peça menor que tem a necessidade de corresponder às dimensões da "história nacional" - ou qualquer que seja o nome que a ela se atribua -, como se dela fosse um apêndice. Uma vez tendo clareza sobre o que se compreende pela dimensão local da história, poderemos entender que as relações de poder, praticadas em dada configuração entendida como local, dispõem de forças e práticas que, mesmo mantendo estreitos diálogos com outras relações e outras práticas ditas nacionais ou globais - não estão submetidas a elas em uma relação de determinação.

A configuração local da história mantém relações de proximidade com a chamada história nacional, mas, também, de distanciamento. Ela é construída por práticas e relações da chamada história local, nacional e global; essas são relações de força, cuja composição não é de fácil distinção. Isso significa reconhecer que não podemos esperar encontrar, em dada configuração da dimensão local da História, um recorte em miniatura da história nacional ou global, mesmo que encontremos traços e sinais semelhantes. Em outras palavras, a dimensão local da História não é um simples e diminuto pedaço de uma história maior. Não é a consequência daquilo que teria ocorrido na história nacional. Se as tintas com as quais se pinta a dimensão local da História são análogas às que desenham as experiências da chamada história nacional, a tonalidade pode sofrer variação, e a tela, assim, ganhar outros tons, outros traçados e, por que não, outras cores. Entretanto, não podemos tampouco esperar que a dimensão local se constitua como uma história independente ou alheia ao que se passa em dada dimensão macro das relações de poder que constroem, historicamente, as experiências, como se não existissem, entre as dimensões local e nacional, pressões, abalos e ressonâncias.

Acredito que problematizar as "dimensões locais da história" pode contribuir para evitarmos certos reducionismos. Ou seja, o professor pode ensinar/ estudar/pesquisar a história do bairro, da rua e da cidade - onde se encontra a escola, por exemplo -, sem a necessidade de enquadrar os acontecimentos, ou compreendê-los pelas lentes de uma "história local" como convencionalmente costuma ser apreendida. Em outras palavras, é possível ensinar os conteúdos que representam as experiências históricas próximas ao universo de vivência dos estudantes sem limitar as reflexões a uma interpretação que 
compreenda os acontecimentos da chamada "história local" como se fossem determinados pelas dimensões espaciais ou resultantes de uma "história maior", ou nacional, se quisermos.

O professor pode deslocar o ângulo de percepção movido pelo fundamento básico da Ciência Histórica ao compreender que as experiências são singulares no tempo e no espaço. Que a construção histórica dos acontecimentos da rua, do bairro ou da cidade não está determinada pelas forças externas de uma história supostamente nacional ou global. Pode potencializar a interpretação mostrando que os homens e mulheres que habitam os espaços onde as histórias são construídas são sujeitos que atuam e interferem na construção e nos desdobramentos das experiências. Que fazem escolhas, constroem redes de sociabilidades, criam sindicatos, associações de bairro, que têm poder e tensionam as relações, interferindo no processo de construção das histórias.

O professor pode transitar pelos documentos, resultantes das experiências compartilhadas pelos estudantes, como cartas, fotografias, diários, coleções de discos, álbuns de família. Pode também fazer uma pesquisa sobre os blogs ou perfis de redes sociais - compreendendo-os como documentos - criados pelos próprios estudantes ou os mais acessados por eles, e pontuar questões relativas aos diferentes suportes materiais pelos quais os homens e mulheres registram suas histórias em diferentes experiências de tempo.

Seguindo essa linha de interpretação, o professor pode da mesma forma explorar os conteúdos registrados nesses diferentes documentos, além de entender as distintas formas de preservação e armazenamento dos dados. Pode potencializar, por conseguinte, a interpretação ao mostrar as tecnologias disponíveis em cada momento a partir dos indícios que as fontes usadas permitem. Pode igualmente demonstrar e compreender as diferentes maneiras e técnicas pelas quais os homens registram suas experiências.

Preocupado em compreender a "configuração local da história", o professor pode explorar as singularidades da história ensinada - ou pesquisada - pontuando as diferenças e/ou semelhanças com outras histórias que também convivem no mesmo bairro ou cidade. Pode pontuar as diferenças e semelhanças construídas no tempo e percebidas, por exemplo, nas mudanças arquitetônicas das casas, das ruas, das sinalizações em vias públicas, na construção de rotas de transportes públicos, na construção de escolas, hospitais e universidades. Pode direcionar as reflexões para entender que as histórias ensinadas 
e/ou pesquisadas, por serem construídas em determinado espaço, não cabem naquelas concepções que geralmente representam a chamada história local.

Diante do narrado, apenas iniciamos os trabalhos com a "lavagem da roupa”. Estamos, por assim dizer, nas primeiras lavagens e, como disse Graciliano Ramos, é preciso, ainda, lavar e esfregar outras vezes, pôr anil, torcer, lavar mais uma vez, enxaguar, torcer e estender a roupa lavada. Nessa perspectiva, deve-se reconhecer que ainda temos muito que avançar na escrita e na reflexão acerca das relações que envolvem a História e a história local. Até a "escrita ficar limpa e ser pendurada no varal para secar", ainda temos muito trabalho à frente. Uma atividade complexa diante das tensões, dos desafios e das relações estabelecidas para quem se aventura a "lavar esse tipo de roupa". Ou seja, para quem escreve e/ou ensina a história, já que, nesse ato, as palavras não podem servir de enfeites, de ilustrações. Elas precisam dizer aquilo que necessita ser dito. Nesse sentido a importância em problematizar alguns sentidos e significados que são atribuídos à história local, e em demonstrar alguns dos desafios que se apresentam para as diferentes apropriações pelas quais essa história tem sido mobilizada.

\section{REFERÊNCIAS}

ALVES, Lynn R. G. Game over: jogos eletrônicos e violência. São Paulo: Futura, 2005. ASSMAN, Hugo (Org.) Redes digitais e metamorfose do aprender. Petrópolis, RJ: Vozes, 2005.

BITTENCOURT, Circe Maria F. Ensino de história: fundamentos e métodos. São Paulo: Cortez, 2009.

BOURDIN, Alain. A questão do local. Trad. Orlando dos Santos Reis. Rio de Janeiro: DP\&A, 2001.

CERTEAU, Michel de. A escrita da história. Trad. Maria de Lourdes Menezes. Rio de Janeiro: Forense Universitária, 2007.

CHAVES, Elisgardenia Oliveira. Educação Patrimonial e ensino de História. História e Ensino, Londrina, v.19, n.2, 2013. Disponível em: http://www.uel.br/revistas/uel/ index.php/histensino/article/download/16116/14144; acesso em: 1 jun. 2016.

CHARTIER, Roger. À beira da falésia: a história entre certezas e inquietudes. Porto Alegre: Ed. UFRGS, 2002.

DELGADO, Lucilia de A. N.; FERREIRA, Marieta de M. História do tempo presente e ensino de história. Revista História Hoje, São Paulo: Anpuh, v.2, n.4, 2013. 
Disponível em: https://rhhj.anpuh.org/RHHJ/article/viewFile/90/70; acesso em: 28 mar. 2016.

GINZBURG, Carlo. Mitos, emblemas, sinais: morfologia e história. Trad. Federico Carotti. São Paulo: Companhia da Letras, 1990.

GOMES, Ângela Maria de C.; LUCA, Tania Regina de. O ensino de história e o tempo presente. Revista História Hoje, São Paulo: Anpuh, v.2, n.4, 2013. Disponível em: https://rhhj.anpuh.org/RHHJ/article/view/90/70; acesso em: 28 mar. 2016.

GONÇALVES, Márcia de A. História local: o reconhecimento da identidade pelo caminho da insignificância. In: MONTEIRO, Ana Maria; GASPARELLO, Arlette M.; MAGALHÃES, Marcelo de S. (Org.) Ensino de história: sujeitos, saberes e práticas. Rio de Janeiro: Mauad X, 2007.

GUIMARÃES, Selva. Didática e prática de ensino de história. 13.ed. Campinas, SP: Papirus, 2012.

HARTOG, François. Tempo e patrimônio. Varia História, Belo Horizonte, v.22, n.36, jul./dez. 2006. Disponível em: http://www.scielo.br/pdf/vh/v22n36/v22n36a02. pdf; acesso em: 15 set. 2015.

KOSELLECK, Reinhart. Futuro passado: contribuição à semântica dos tempos históricos. Rio de Janeiro: Contraponto; Ed. PUC-Rio, 2006.

LEVI, Giovanni. Sobre a micro-história. In: BURKE, Peter (Org.) A escrita da história: novas perspectivas. São Paulo: Ed. Unesp, 2011.

LEOPOLDINO, Maria Aparecida. A leitura de textos literários no ensino de história escolar: entrelaçando percursos metodológicos para o trato com os conceitos de tempo e espaço. Revista História Hoje, São Paulo: Anpuh, v.4, n.8, p.130-151, 2015. Disponível em: https://rhhj.anpuh.org/RHHJ/article/download/189/145; acesso em: 9 mar. 2016.

MAGALHÃES, Marcelo de S; GONTIJO, Rebeca. O presente como problema historiográfico na Primeira República em dois manuais escolares. Revista História Hoje, São Paulo: Anpuh, v.2, n.4, 2013. Disponível em: https://rhhj.anpuh.org/RHHJ/ article/view/91; acesso em: 6 jul. 2016.

MATTA, Alfredo. Tecnologia de aprendizagem em rede e ensino de história: utilizando comunidades de aprendizagem e hipercomposição. Brasília: Líber Livro, 2006.

MATTOZZI, Ivo. Currículo de história e educação para o patrimônio. Educação em Revista, Belo Horizonte, n.47, 2008. Disponível em: http://www.scielo.br/scielo. php?pid=S0102-46982008000100009\&script=sci_abstract\&tlng=pt; acesso em: 15 jun. 2015.

MIRANDA, Sonia Regina. Temporalidade e cotidiano escolar em rede de significações: desafios didáticos na tarefa de educar para a compreensão do tempo. Revista História Hoje, São Paulo: Anpuh, v.2, n.4, 2013. Disponível em: https://rhhj.anpuh. org/RHHJ/article/view/92; acesso em: 20 set. 2015. 
MORTATTI, Maria do Rosário L. Na história do ensino da literatura no Brasil: problemas e possibilidades para o século XXI. Educar em Revista, Curitiba: Ed. UFPR, n.52, p.23-43, abr./jun. 2014. Disponível em: http://www.scielo.br/pdf/er/n52/03. pdf; acesso em: 20 set. 2105.

ORIÁ, Ricardo. Construindo o Panteão dos Heróis Nacionais: monumentos à República, rituais cívicos e o ensino de História. Revista História Hoje, São Paulo: Anpuh, v.3, n.6, p.43-66, 2014. Disponível em: https://rhhj.anpuh.org/RHHJ/article/view/137; acesso em: 21 jun. 2016.

Memória e ensino de história. In: BITTENCOURT, Circe Maria F. (Org.) O saber histórico na sala de aula. São Paulo: Contexto, 1998.

OSSANA, Edgardo. Una alternativa en la enseñanza de la Historia: enfoque desde el local, lo regional. In: VASQUEZ, Josefina Z. (Org.) Enseñanza de la historia. Buenos Aires: s.n., 1994. (Colección Interamer, 29).

PELEGRINI, Sandra de Cássia A.; FUNARI, Pedro Paulo A. O que é patrimônio cultural imaterial. São Paulo: Brasiliense, 2008.

RAMOS, Graciliano. Linhas tortas. São Paulo: Martins, 1962.

REVEL, Jacques. Microanálise e construção do social. In: (Org.) Jogos de escalas: a experiência da microanálise. Rio de Janeiro: Ed. FGV, 1998.

SAMUEL, Raphael. História local e história oral. Revista Brasileira de História, São Paulo: Anpuh, v.9, n.19, p.219-243, 1990. Disponível em: http://www.anpuh.org/ arquivo/download?ID_ARQUIVO=3887; acesso em: 28 mar. 2015.

SANTOS, Milton. Pensando o espaço do homem. São Paulo: Edusp, 2009.

SILVA, Marcos. Ensino de História e novas tecnologias. (Artigo avulso, publicação eletrônica). Aracaju: UFS, 2012. Disponível em: http://www.educadores.diaadia. pr.gov.br/arquivos/File/fevereiro2012/historia_artigos/2silva_artigo.pdf.

SCHMIDT, Maria Auxiliadora. O ensino de história local e os desafios da formação da consciência histórica. In: MONTEIRO, Ana Maria; GASPARELLO, Arlette M.; MAGALHÃES, Marcelo de S. (Org.) Ensino de história: sujeitos, saberes e práticas. Rio de Janeiro: Mauad X, 2007.

\section{NOTAS}

${ }^{1}$ O Encontro ocorreu entre os dias 6 e 8 de março de 2017, no Instituto de Ciência e Tecnologia do Pará, na cidade de Marabá. Deixo aqui expressos meus agradecimentos aos organizadores do evento pelo convite: a professora Anna Carolina de Abreu Coelho e o Grupo de Pesquisa "O local e o global: história, memória e natureza no sul e sudeste do Pará".

2 Para uma reflexão envolvendo História, ensino e patrimônio, ver CHAVES, 2013; MATTOZZI, 2008; PELEGRINI; FUNARI, 2008; HARTOG, 2006; ORIÁ, 1998; 2014.

${ }^{3}$ Consultar: CHARTIER, 2002; GUIMARÃES, 2012; MORTATTI, 2014; LEOPOLDINO, 2015. 
${ }^{4}$ Para ampliar as discussões, ver: ALVES, 2005; ASSMAN, 2005; MATTA, 2006; SILVA, 2012.

${ }^{5}$ Para expandir as discussões, consultar: GOMES; LUCA, 2013; DELGADO; FERREIRA, 2013; MAGALHÃES; GONTIJO, 2013; MIRANDA, 2013.

${ }^{6}$ As referências acerca da história local encontram-se ao longo do texto e na bibliografia do presente artigo.

${ }^{7}$ Sirvo-me aqui das discussões promovidas pelo historiador Carlo Ginzburg acerca do chamado "paradigma indiciário". Para ampliar as discussões, consultar GINZBURG, 1990.

${ }^{8}$ Também podemos encontrar essa linha de interpretação nas reflexões promovidas pelo geógrafo Milton Santos. Para ele, o espaço é o efeito de um conjunto de múltiplas forças resultantes das relações humanas no tempo. Nesse sentido, Santos argumenta que "todo espaço social pode ser objeto de uma análise formal, estrutural e funcional" (SANTOS, 2009, p.55). Ou seja, a concepção conceitual de "espaço", assim como de "local", é uma construção intelectual.

${ }^{9}$ Não podemos incorrer, portanto, em afirmações apressadas como se houvesse complementaridade ou similaridade entre história local e micro-história. É oportuno enfatizar que a micro-história surgiu, segundo Jacques Revel, "como uma resposta às limitações óbvias daquelas interpretações da história social, que em sua busca de regularidade, dá proeminência a indicadores supersimples" (REVEL apud LEVI, 2011, p.162). E, para Giovanni Levi, a micro-história se caracteriza, fundamentalmente, pela "redução de escala, o debate sobre a racionalidade, a pequena indicação como um paradigma científico, o papel do particular (não, entretanto, em oposição ao social), a atenção à capacidade receptiva e à narrativa, uma definição específica de contexto e a rejeição do relativismo" (LEVI, 2011, p.162).

${ }^{10}$ Jornal produzido na versão impressa e on-line, com sede na cidade de Marabá, Pará. O jornal foi fundado em 1983 pelo jornalista Mascarenhas Carvalho da Luz, com circulação quinzenal. Depois, passou a ser semanal e, atualmente, apresenta três edições por semana. Sua versão on-line encontra-se disponível em: http://www.ctonline.com.br/?inicial; acesso em: 2 mar. 2017.

${ }^{11}$ Jornal produzido na versão impressa e on-line, com sede na cidade de Caruaru, Pernambuco. O jornal Vanguarda foi fundado em 1932 por José Carlos Florêncio, com quatro páginas cada exemplar e tiragem inicial de mil exemplares, e circulava pelas principais cidades do Agreste de Pernambuco e na capital, Recife. Sua versão on-line encontra-se disponível em: http://www.jornalvanguarda.com.br/v2/index.php; acesso em: 2 mar. 2017.

Artigo recebido em 20 de julho de 2017. Aprovado em 15 de junho de 2018. 